\title{
Induction of apoptosis in tilapia, Oreochromis aureus Steindachner, and in TO-2 cells by Staphylococcus epidermidis
}

\author{
S-L Huang ${ }^{1,2}$, I-C Liao ${ }^{3}$ and S-N Chen ${ }^{2}$ \\ 1 Lu-Kang Branch, Taiwan Fisheries Research Institute, Changhua, Taiwan \\ 2 Department of Zoology, National Taiwan University, Taipei, Taiwan \\ 3 Taiwan Fisheries Research Institute, Keelung, Taiwan
}

\begin{abstract}
This study describes apoptosis induced in vivo and in vitro in tilapia, Oreochromis aureus Steindachner, by Staphylococcus epidermidis. In an in vivo experiment, tilapia were challenged using viable $S$. epidermidis and its cultured supernatant, respectively. Apoptosis was predominantly detected in lymphocytes and macrophages in spleen and kidney. Apoptotic figures were observed occasionally in the brain, liver, gonad, mesentery, stomach, intestine and skeletal muscle of infected fish. In an in vitro experiment, TO-2 cells treated with brain heart infusion broth supernatant of the bacteria after $48 \mathrm{~h}$ revealed that the supernatant was able to induce the cell apoptosis. Fragmented DNA was also detected $48 \mathrm{~h}$ after treatment using $1.5 \%$ agarose gel electrophoresis. The smallest multimeric DNA fragment was approximately 180-bp in length. Results of both the in vitro and in vivo experiments showed that products of the bacteria could induce tilapia cell apoptosis.
\end{abstract}

\section{Introduction}

Pathogenicity initiated by Staphylococcus epidermidis in cultured tilapia in Taiwan was confirmed in a previous study (Huang, Chen, Shei, Liao \& Chen 1999). In the pathological study performed on the tissues of infected fish, numerous electrondense particles were observed in the brain, spleen, kidney, pancreas, liver, intestine, stomach, mesen-

Correspondence Professor SN Chen, Department of Zoology, National Taiwan University, Taipei, Taiwan 107 tery, gonad and skeletal muscle of diseased tilapia. The particles were suspected to be apoptotic bodies caused by infection with $S$. epidermidis (Huang et al. 1999).

Since there was no report on apoptosis induced by $S$. epidermidis, it was unknown whether the bacteria caused the fish cell apoptosis. To demonstrate bacterial induction of apoptosis, tilapia and TO-2 cells were treated by $S$. epidermidis viable cells and/or the supernatant. The results showed that the bacterias' supernatant can induce apoptotic bodies forming either in tilapia or TO-2 cells, thus suggesting the electron-dense particles observed previously were indeed apoptotic bodies.

\section{Materials and methods}

\section{Bacteria}

Staphylococcus epidermidis strain LK0728, previously isolated from the spleen of diseased tilapia in July 1993 in Lukang, Changhua, Taiwan, was used in this study.

\section{Bacterium and its supernatant}

Collection of the bacteria was performed by using 6-cm discs of dialysis membrane (molecular weight cut-off of 6000-8000, Spectra/Por 1) overlaid on brain heart infusion agar (BHIA) and by spreading $0.2-0.3 \mathrm{~mL}$ of overnight cultured broth with a sterilized glass rod (Inamura, Muroga \& Nakai 1984). The bacteria were collected by washing the
(C) 2000

Blackwell Science Ltd 
dialysis membrane in $5 \mathrm{~mL}$ of saline $(0.85 \% \mathrm{NaCl})$ after $24 \mathrm{~h}$ of incubation at $30^{\circ} \mathrm{C}$.

Bacterial suspension at a density of $3.24 \times 10^{9}$ cfu $\mathrm{mL}^{-1}$ was centrifuged at $5000 \times \boldsymbol{g}$ for $20 \mathrm{~min}$, at $4{ }^{\circ} \mathrm{C}$ (Hitachi 05PR22; Hitachi, Tokyo, Japan). The supernatant was filtered through a sterilized $0.22-\mu \mathrm{m}$ filter. The filtrate was designated as saline supernatant.

Conversely, S. epidermidis cultured on brain heart infusion broth (BHIB) at $30{ }^{\circ} \mathrm{C}$ for $24-36 \mathrm{~h}$ was diluted to a density of $3.24 \times 10^{9} \mathrm{cfu} \mathrm{mL}^{-1}$. The bacteria suspension was centrifuged at $5000 \times \boldsymbol{g}$ at $4^{\circ} \mathrm{C}$ for $20 \mathrm{~min}$ and the supernatant was collected and filtered through a sterilized 0.22 $\mu \mathrm{m}$ filter. The filtrate was designated as BHIB supernatant.

\section{In vivo induction of apoptosis}

Experimental animals

Tilapia, Oreochromis aureus Steindachner, fry were reared in a $2 \times 3 \times 1 \mathrm{~m}$ tank with aeration until the body weight was $60-70 \mathrm{~g}$. To judge the health of experimental fish, 10 fish randomly selected were evaluated for several parameters using routine methods before experimentation. These parameters included fish behaviour, external appearance, internal appearance, bacterial isolation and histopathological examination. Healthy tilapia were transferred to and kept in 1000-1 tanks with aeration. The fish were allowed to acclimatize in the tank for at least 2 weeks prior to experimentation. During the course of the experiment, fish were fed with commercial tilapia food and reared at a room temperature of approximately $28^{\circ} \mathrm{C}$.

\section{Challenge}

Tilapia used for the challenge experiment were divided into eight groups, each of 10 fish. Six groups of the experimental fish were injected intraperitoneally (i.p.) with $0.5 \mathrm{~mL}$ of a bacterial suspension at a concentration of $1.34 \times 10^{3}$, $1.34 \times 10^{4}, 1.34 \times 10^{5}, 1.34 \times 10^{6}, 1.34 \times 10^{7}$ and $1.34 \times 10^{9} \mathrm{cfu} \mathrm{mL}^{-1}$, respectively. In addition, one group was injected with $0.5 \mathrm{~mL}$ of saline supernatant and another was administered saline as a control.

\section{Transmission electron microscopy (TEM)}

Kidney, liver and spleen were dissected from the experimentally infected tilapia, fixed in $2.5 \%$ glutaraldehyde for $2 \mathrm{~h}$, post-fixed with $1 \%$ osmium tetroxide at $4{ }^{\circ} \mathrm{C}$ for $1 \mathrm{~h}$, dehydrated in a graded series of ethanol and absolute acetone, and embedded in Spurr's resin (Spurr 1969). Ultrathin sections were then cut with a Sorvall MT $5000(\mathrm{CN}$, USA) ultramicrotome and stained with uranyl acetate and lead citrate, according to procedures described by Frasca \& Parks (1965). The sections were then examined using a Hitachi H-600 electron microscope at $75 \mathrm{kV}$.

\section{In vitro induction of apoptosis \\ Cell line cultures}

The TO-2 (tilapia ovary) cell line was used in this experiment (Chen, Chi, Ueno \& Kou 1983). The cells were routinely cultured in Leibovitz's 15 (L15) medium (Gibco, New Zealand) containing $10 \%$ foetal bovine serum (FBS, Gibco) (L-15 growth medium) at $28{ }^{\circ} \mathrm{C}$.

\section{Phase contrast microscopy}

TO-2 cells incubated with diluted BHIB supernatant (BHIB supernatant mixed with an equal volume of L-15 growth medium) for each consecutive incubation period were observed under an Olympus IM phase contrast microscope. The control used BHIB instead of BHIB supernatant.

\section{Scanning electron microscopy (SEM)}

For SEM observations, TO-2 cells grown on round coverslips were used. To investigate the effect of extracellular products of $S$. epidermidis, the cells were exposed to diluted BHIB supernatant. Selected incubation periods, including $4,7,16,20$, 24, 30, 48, 60, 72, 84, 96 and $108 \mathrm{~h}$ were used. After each incubation period, the coverslips were fixed in $2.5 \%$ glutaraldehyde at $4{ }^{\circ} \mathrm{C}$ for $2 \mathrm{~h}$ and post-fixed in $1 \%$ osmium tetroxide for $1 \mathrm{~h}$, dehydrated in a graded series of ethanol and absolute acetone, and then passed through critical-pointdrying using liquid $\mathrm{CO}_{2}$. After drying, the coverslips were mounted on stubs, coated with carbon, and examined in a scanning electron microscope (S-520 Hitachi, Japan).
(C) 2000

Blackwell Science Ltd 


\section{Fluorescent stain}

Since apoptosis is based on DNA fragmentation, direct morphological evaluation of cells stained with fluorescent dye under light microscopy is required (Eastman 1995). TO-2 cells cultured on a chamber slide (glass slide, polystyrene chambers, Nunc) were exposed to diluted BHIB supernatant for $48 \mathrm{~h}$ at $28^{\circ} \mathrm{C}$. The treated cells were then fixed in pre-cooled $70 \%$ ethanol and stained with $5 \mu \mathrm{g}$ $\mathrm{mL}^{-1}$ of propidium iodide (PI) or $0.1 \%$ acridine orange (AO) (Fraker, King, Lill-Elghanian \& Telford 1995).

\section{DNA extraction}

TO-2 cells $\left(5.8 \times 10^{7}\right.$ cells per $150-\mathrm{cm}^{2}$ flask $)$ subcultured post-24 h were washed twice with $\mathrm{Ca}^{++}, \mathrm{Mg}^{++}$-free phosphate-buffered saline. Subsequently, $40 \mathrm{~mL}$ of the diluted BHIB supernatant was added to the flask. The cultures were incubated at $28^{\circ} \mathrm{C}$ for $24,36,48,60,72$ or $84 \mathrm{~h}$, respectively, before harvesting. After each incubation period, the cells, including suspended cells, were collected and lysed in $1 \mathrm{~mL}$ of lysis buffer solution (5 mM Tris, $20 \mathrm{mM}$ EDTA, 0.5\% Triton $\mathrm{X}-100, \mathrm{pH} 8.0)$ at $4{ }^{\circ} \mathrm{C}$ for $1 \mathrm{~h}$. The cell lysates were then centrifuged at $27000 \times \boldsymbol{g}$ for $20 \mathrm{~min}$ at $4^{\circ} \mathrm{C}$ and the supernatants collected. Extracted genomic DNA was prepared by adding two volumes of phenol-chloroform-isopropyl alcohol (25:24:1) into the supernatant. The DNA was precipitated in absolute ethanol at $-20{ }^{\circ} \mathrm{C}$ overnight. Subsequently, the DNA was collected by centrifugation $(16000 \times \boldsymbol{g}, 10 \mathrm{~min})$ and washed with cold $70 \%$ ethanol, and then air-dried. The crude DNA was resuspended in $0.5 \mathrm{~mL}$ of RNase buffer containing $20 \mu \mathrm{L} \mathrm{mL}^{-1}$ of ribonuclease A. Digestion of RNA was progressed at $37^{\circ} \mathrm{C}$ for $30 \mathrm{~min}$. Genomic DNA obtained using the above methods was dissolved in Tris-EDTA buffer $(10 \mathrm{mM}$ Tris- $\mathrm{Cl}$ and 1 $\mathrm{mM}$ EDTA, $\mathrm{pH}$ 8.0) and electrophoresed in a $1.5 \%$ agarose gel.

\section{Results}

\section{In vivo experiment}

\section{TEM examination}

TEM observations showed that $S$. epidermidis was phagocytosed by macrophages in the spleen $48 \mathrm{~h}$ after i.p. injection (Fig. 1).
In vivo experimental fish, challenged using the viable bacteria after $48 \mathrm{~h}$, demonstrated cytoplasmic-condensed or cytoplasmic-vacuolized cells scattered throughout the spleen. Morphological characteristics of apoptosis, such as extensive chromatin clumping, nuclear fragmentation, cytoplasmic condensation and membrane blebbing were observed in splenic lymphocytes. During early stages of apoptosis, condensed chromatin with sharply delineated edges abutted the inner surface of the nuclear envelope (Fig. 2). Convolution of the cell and nuclear outlines and small masses of condensed chromatin were also observed. Multiple nuclear fragments, enclosed by double membranes and with varying chromatin content, were also noted in the lymphocytes. Apoptotic bodies observed in the lymphocytes could be distinguished from bacteria within macrophages since the latter possessed a significant cell wall. Apoptotic bodies were also detected in the kidney and liver. Apoptosis, however, was most severe in the spleen and kidney. More extensive apoptosis in these tissues was observed after challenge with a higher dose of the viable bacterium or saline supernatant of the bacterium.

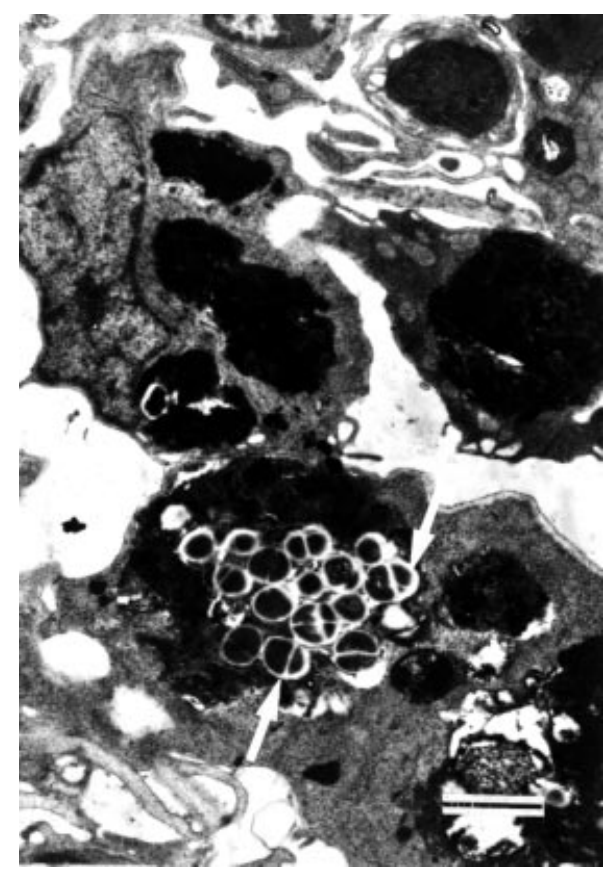

Figure 1 TEM micrograph showing Staphylococcus epidermidis phagocytosed by a lymphocyte in the spleen. Arrow indicates the bacterial mass. Dividing bacteria with distinctive cell walls were observed (bar $=2 \mu \mathrm{m})$.
(C) 2000

Blackwell Science Ltd 


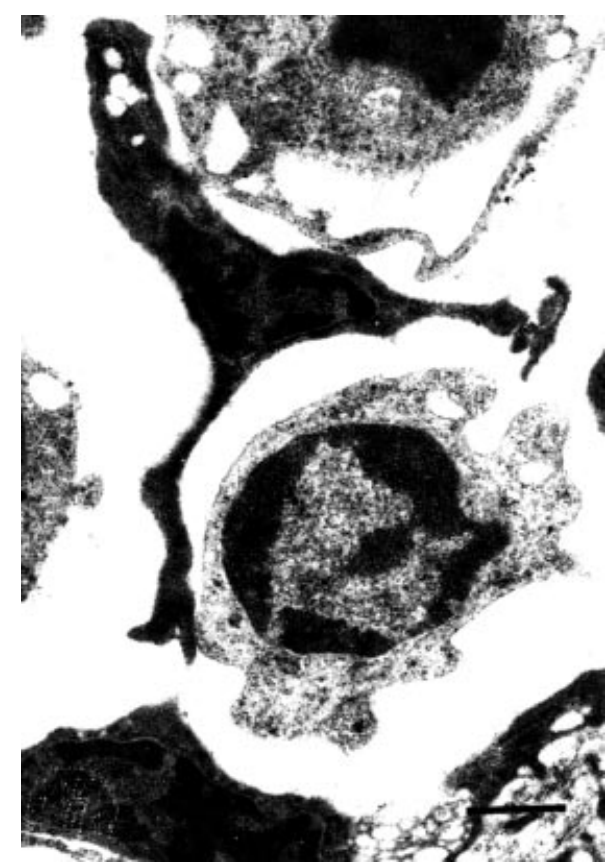

Figure 2 TEM micrograph of a lymphocyte in the spleen of tilapia $48 \mathrm{~h}$ after challenge by $S$. epidermidis. Condensed chromatin with sharply delineated edges abuts the inner surface of the nuclear envelope (bar $=800 \mathrm{~nm}$ ).

\section{In vitro experiment}

\section{Phase microscopy examination}

In the in vitro experiment, TO-2 cells treated with the BHIB supernatant showed gradual changes, including rounding, shrinking, detachment and floating into the medium, and numerous small particles budding from the cell. With increasing incubation time, more and more small oval-shaped particles appeared at the cell surface (Fig. 3) and were released into the medium. The percentage of detached cells increased and reached $50-70 \%$ after $96 \mathrm{~h}$ of incubation. In contrast, no such particles were found in the control groups.

\section{TEM examination}

At 4-7 h after BHIB supernatant exposure, an abnormally convoluted nuclear outline was observed in a few cells. Other observable abnormal features after $24 \mathrm{~h}$ of incubation included chromatin aggregation, abnormal convolution and indentation of the nuclear outline, vacuolized and condensed cytoplasm, and lobulation or fragmentation of the nuclei - these being similar to the features of apoptosis. Numbers of the abnormal cells increased with time. Furthermore, oval-shaped electron-dense particles in the cells were readily observed after $48 \mathrm{~h}$ of incubation.

\section{SEM examination}

TO-2 cells treated with the diluted BHIB supernatant after $4 \mathrm{~h}$ were distinguishable from normal TO-2 cells by their altered morphology. Normal TO-2 cells had numerous microvilli on the surface (Fig. 4A). TO-2 cells showed surface protuberances on the nuclear region after $4 \mathrm{~h}$ of incubation (Fig. $4 \mathrm{~B})$. Numerous protuberances were observed on the surface after treatment for $7 \mathrm{~h}$ (Fig. 4C). Round to oval-shaped bodies were observed budding from the cell surface after $16 \mathrm{~h}$ of treatment (Fig. 4D). The extent of such morphological alterations of TO-2 cells increased with incubation time. Sixty hours after incubation, microvilli were hard to observe and many oval-shaped bodies budding from the cell surface were observed (Fig. 4E). The bodies covered the whole cell surface after 72 $\mathrm{h}$ of incubation (Fig. 4F).

\section{Fluorescent stain}

Morphology of apoptotic cells, as characterized by AO and PI staining, showed that apoptotic cells with 'dots' of condensed chromatin appeared green, and the 'dots' of condensed chromatin showed a red colour by PI staining.

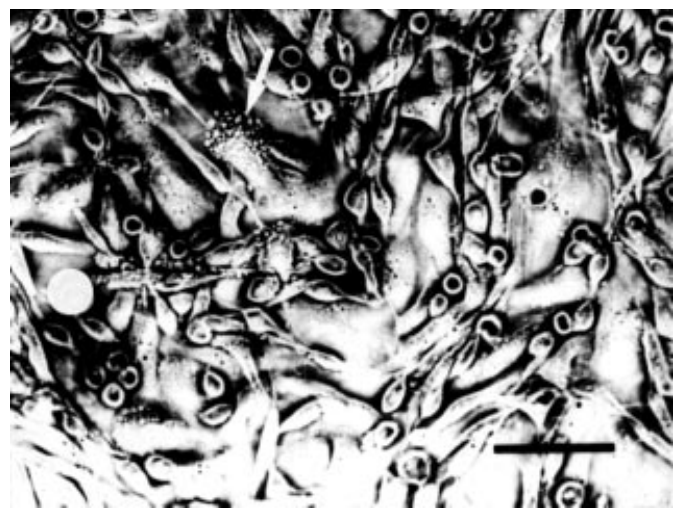

Figure 3 Phase contrast micrograph of TO-2 cells after $48 \mathrm{~h}$ of treatment with the supernatant of $S$. epidermidis. Numerous small particles are seen budding from the cells (arrow) (bar $=50$ $\mu \mathrm{m})$.
(C) 2000

Blackwell Science Ltd 


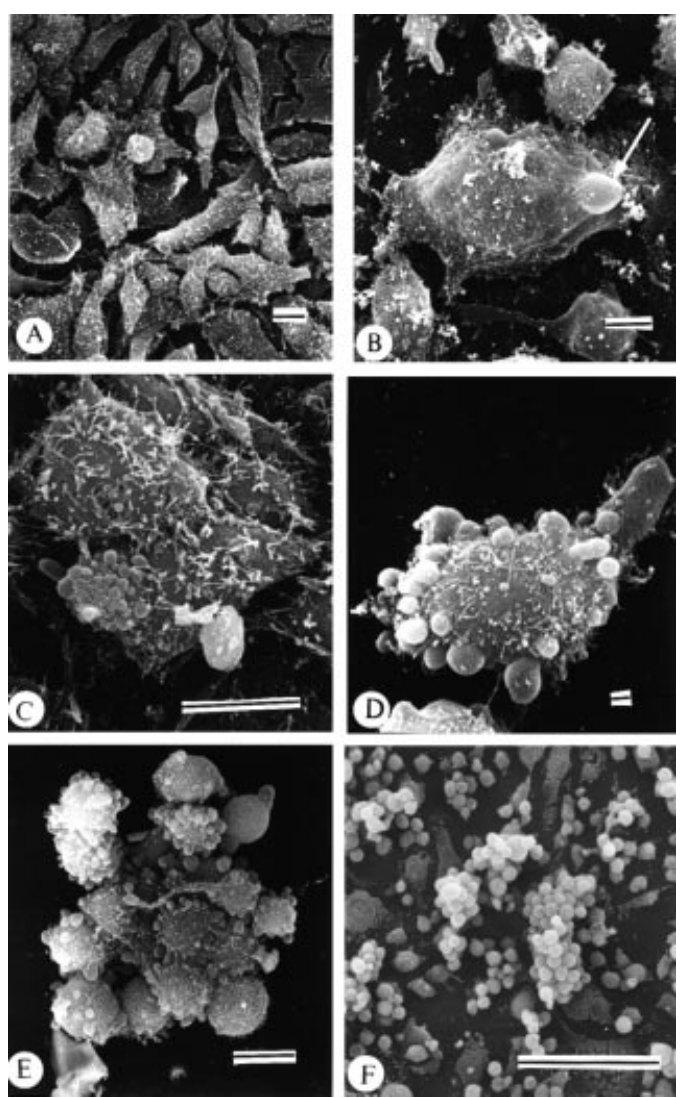

Figure 4 Scanning electron micrographs of TO-2 cells. (A) Normal TO-2 cells. Note numerous microvilli on the cell surface. (B) TO-2 cells after $4 \mathrm{~h}$ of treatment with the supernatant of S. epidermidis. Note the surface protuberance (arrow). (C) TO-2 cells after $7 \mathrm{~h}$ of treatment with the supernatant. Some cells show obvious surface protuberances. (D) TO-2 cells after $16 \mathrm{~h}$ of treatment, round to oval-shaped bodies are seen budding from the surface. Extensive apoptosis morphologies were observed after 60- and 72-h treatments as shown in E and $\mathrm{F}$, respectively (bar $=7.5 \mu \mathrm{m}$ ).

\section{$1.5 \%$ agarose gel electrophoresis}

Results of genomic DNA electrophoresis of TO-2 cells using a 1.5\% agarose gel are shown in Fig. 5. Fragmented DNA exhibited the typical 'ladder' pattern when TO-2 cells were incubated with the diluted BHIB supernatant. Fragmented DNA was detected extensively after $48 \mathrm{~h}$ of incubation, whereas no significant fragmented DNA was detected after 24 or $36 \mathrm{~h}$ of incubation. The concentration of DNA fragments increased with incubation time. The smallest multimeric DNA fragment was approximately $180 \mathrm{bp}$.

\section{Discussion}

Apoptosis is a physiological and pathological process of cell deletion that functions as an essential mechanism of normal tissue homeostasis and it may play a critical role in relation to disease status (Kerr, Wyllie \& Currie 1972; Columbano 1995; Wertz \& Hanley 1996). According to the description by Kerr et al. (1972), the morphological characteristics of apoptosis occurring in infected cells consist of extensive chromatin clumping, nuclear fragmentation, cytoplasmic condensation and membrane blebbing. Under TEM, apoptotic bodies appear as membrane-bound electron-dense particles resulting from nuclear fragmentation. At the early stages, apoptosis is characterized by convolution of nuclear outline and segregation of condensed, sharply circumscribed chromatin. This condensation and fragmentation is caused by DNA digestion (Kerr et al. 1972). In the next phase, the nucleus fragments and further condensation of cytoplasm is associated with extensive cell surface protrusion. Subsequently, apoptotic bodies of vary-

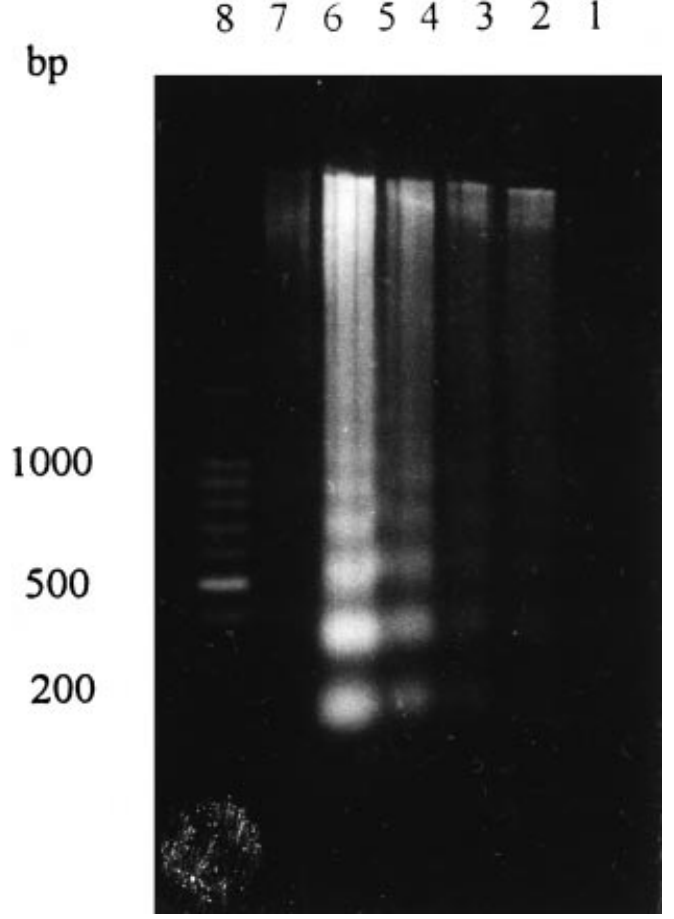

Figure 5 Gel electrophoresis of genomic DNA of TO-2 cell using $1.5 \%$ agarose showing fragmented DNA after $48 \mathrm{~h}$ of treatment with the $S$. epidermidis supernatant. The amount of the DNA fragment increased with time. Lanes 1-6, treated with supernatant after $24,36,48,60,72$ and $84 \mathrm{~h}$, respectively. Lane 7 is a control and lane 8 is a 100-bp DNA ladder marker. 
ing size and composition separate from the surface protuberances.

In this study, the processes of apoptosis were observed either in tissues or in TO-2 cells after $48 \mathrm{~h}$ of treatment using $S$. epidermidis or its culture supernatant. The affected cells observed under TEM revealed typical apoptosis characteristics, such as chromatin clumping, nuclear fragmentation and cytoplasmic condensation. Membrane blebbing, which is also a characteristic of apoptosis, was observed in supernatant-treated TO-2 cells under SEM examination.

In this study, nuclear fragmentation was also observed in cells stained with PI or AO. In TO2 cells treated with the supernatant for $48 \mathrm{~h}$, fragmented DNA was also detected using agarose gel electrophoresis. The smallest multimeric DNA fragment observed, approximately $180 \mathrm{bp}$, has also been considered a characteristic of apoptosis (Kerr et al. 1972). Thus, it suggested that the bacterial supernatant could cause apoptosis both in tilapia tissue in vivo and in the TO-2 cell.

Although it is not known which component caused the cell to undergo apoptosis in this experiment, lipopolysaccharide-induced apoptosis in thymic lymphocytes in vivo was observed by Yokoshi, Inoue, Yokoo, Kimura \& Kato (1989). Further experiments are necessary to determine the components in this study that induced the cell apoptosis.

In a previous study (Huang et al. 1999), electron-dense particles were revealed by TEM in numerous tissues, including the brain, spleen, kidney, pancreas, liver, intestine, stomach, mesentery, gonad and skeletal muscle of $S$. epidermidisinfected fish. These particles were identical in morphology to the apoptotic bodies observed in this study. Apoptotic bodies were easily distinguished from melanosomes by both their morphology and their location in the cell. Melanosomes, observed under TEM, are oval to long, rod-shaped structures with a single-layer membrane and they are usually scattered throughout the cytoplasm. Apoptotic bodies are double membrane-bound, round to oval in shape, and of varying size, and they are usually concentrated together in the centre of the cell. Moreover, the apoptotic cell usually has a denser cytoplasm than the melanocyte. Apoptotic bodies can also be distinguished from $S$. epidermidis since the cell wall of the bacterium is very distinctive. Those electron-dense particles found in various tissues in naturally infected tilapia with $S$. epidermidis were considered to be apoptotic bodies.

The supernatant of $S$. epidermidis was shown to induce tilapia cell apoptosis and cause TO-2 cell death. This suggests that the pathogenicity of the bacterium was due to the toxicity of the bacterial product that induced the apoptosis. The functional components of this entity are still unknown and need to be investigated further.

\section{References}

Chen S.N., Chi S.C., Ueno Y. \& Kuo G.H. (1983) A cell line derived from tilapia ovary. Fish Pathology 18, 13-18.

Columbano A. (1995) Cell death: current difficulties in discriminating apoptosis from necrosis in the context of pathological processes in vivo. Journal of Cellular Biochemistry 58, 181-190.

Eastman A. (1995) Assays for DNA fragmentation, endonucleases, and intracellular $\mathrm{pH}$ and $\mathrm{Ca}^{2+}$ associated with apoptosis. In: Cell Death (ed. by L.M. Schwartz \& B.A. Osborne), pp. 41-55. Academic Press, San Diego, CA.

Fraker P.J., King L.E., Lill-Elghanian D. \& Telford W.G. (1995) Quantification of apoptotic events in pure and heterogeneous populations of cells using the flow cytometer. In: Cell Death (ed. by L.M. Schwartz \& B.A. Osborne), pp. 57-76. Academic Press, San Diego, CA.

Frasca J.M. \& Parks V.E. (1965) A routine technique for double staining ultrathin sections using uranyl and lead salts. The Journal of Cell Biology 25, 157.

Huang S.L., Chen W.C., Shei M.C., Liao E.C. \& Chen S.N. (1999) Studies on epizootiology and pathogenicity of Staphylococcus epidermidis in tilapia (Oreochromis spp.) cultured in Taiwan. Zoological Studies 38, 178-188.

Inamura H., Muroga K. \& Nakai T. (1984) Toxicity of extracellular products of Vibrio anguillarum. Fish Pathology 19, 89-96.

Kerr J.F.R., Wyllie A.H. \& Currie A.R. (1972) Apoptosis: a basic biological phenomenon with wide ranging implications in tissue kinetics. The British Journal of Cancer/Cancer Research Campaign 26, 239-257.

Spurr A.R. (1969) A low-viscosity epoxy resin embedding medium for electron microscopy. Journal of Ultrastructure Research 26, 31-43.

Wertz I.E. \& Hanley M.R. (1996) Diverse molecular provocation of programmed cell death. Trends in Biochemical Science 21, 359-364.

Yokoshi T., Inoue Y., Yokoo J., Kimura Y. \& Kato N. (1989) Retention of bacterial lipopolysaccharide at the site of subcutaneous injection. Infection and Immunity 57, $1786-1791$. 